\title{
The Interplay among Organisational Learning Culture, Agility, Growth, and Big Data Capabilities
}

\author{
Dilek Cetindamar ${ }^{1, *(\mathbb{D},}$, Mile Katic ${ }^{1}$, Steve Burdon ${ }^{1}$ and Ayse Gunsel ${ }^{2}$ \\ 1 Faculty of Engineering and IT, University of Technology Sydney, Ultimo 2007, Australia; \\ mile.katic@uts.edu.au (M.K.); steve.burdon@uts.edu.au (S.B.) \\ 2 Department of Business Administration, Kocaeli University, Kocaeli 41001, Turkey; \\ ayse.gunsel@kocaeli.edu.tr \\ * Correspondence: dilek.ck@uts.edu.au
}

Citation: Cetindamar, D.; Katic, M.; Burdon, S.; Gunsel, A. The Interplay among Organisational Learning Culture, Agility, Growth, and Big Data Capabilities. Sustainability 2021, 13, 13024. https://doi.org/ $10.3390 /$ su132313024

Academic Editor: Víctor Jesús García-Morales

Received: 21 October 2021 Accepted: 21 November 2021 Published: 24 November 2021

Publisher's Note: MDPI stays neutral with regard to jurisdictional claims in published maps and institutional affiliations.

Copyright: (c) 2021 by the authors. Licensee MDPI, Basel, Switzerland. This article is an open access article distributed under the terms and conditions of the Creative Commons Attribution (CC BY) license (https:/ / creativecommons.org/licenses/by/ $4.0 /)$.

\begin{abstract}
This paper examines how an organisational learning culture impacts organisational agility by developing a model based on dynamic capabilities. The model treats agility as a dynamic capability and explains how an organisational learning culture (OLC) triggers a chain reaction through its influence on organisational agility (OA) that ultimately results in company growth. This paper also investigates the role of big data capabilities in transferring learning outcomes into dynamic capabilities. The model is tested through data collected from a survey of 138 Australian companies. Partial least squares structural equation modeling is adopted to empirically demonstrate how agility fully mediates the impact of the learning culture on growth. In addition, this paper further sheds light on the moderating role of big data competencies on the effects of OLC on OA. After presenting the results with implications to theory and practice, the paper ends with suggestions for future studies.
\end{abstract}

Keywords: organisational learning culture; organisational agility; big data capabilities; innovation; growth

\section{Introduction}

Recent times have observed an increased interest in the potential of key technologies such as big data in enabling organisational agility (OA) within complex, dynamic, and innovative business environments [1-3]. OA differs from organisational change in that the former shows how leaders can become proactive and transform themselves when faced with unpredictability, while the latter deals with leaders driving top-down change [4]. Hence, OA is conceptualised as a dynamic capability that operates at the organisational level to enable an organisation to cope in uncertain environments [5]. In addition, agility is seen as a crucial capability to detect and seize competitive opportunities to generate innovations [6]. Indeed, a recent investigation of Amazon's global growth is linked to its agility capability [7]. In summation, OA helps leaders and managers to build an ability to sense environmental changes and proactively respond to them [8]. That is why agility is a desirable goal for any innovative organisation.

OA requires a shift from managerial control mindsets to "managing by all" (p. 118 [9]). Hence, managers are expected to care about their employees and empower them to build firm-level capabilities to deliver agile capacity to firms $[10,11]$. This mindset, however, does not happen by itself. Managers should further embrace a learning culture at the organisational level [5], where this so-called organisational learning culture (OLC) is considered "a collection of organisational conventions, values, and practices that encourage employees in an organisation to develop critical skills, knowledge, and competence through continuous learning processes" (p. 584 [12]). Indeed, given such an intuitive significance of the concept of OLC and OA in delivering better performance outcomes for firms, there has been a complementary surge in research on the topic [5,8], though it seems the resultant impacts of OA and OLC on firm performance are not so clear $[13,14]$. 
For instance, earlier studies have recognised that an effective OLC can incur some positive performance implications for organisations [15]. However, when investigating firm performance from both the financial and non-financial perspectives, some found a direct and positive link between the OLC and organisational differences between the two [16]. Here, there appeared to be no direct link between the OLC and financial performance instead of occurring through non-financial performance vis-a-vis employee, customer, and supplier performance [16]. This is something more recent work has also come to find in the sense of employee empowerment mediating the impact of the OLC on organisational performance [17]. Conversely, a study [16] found that a direct impact could be observed between the OLC and financial performance. More recent findings also provide some insight into the complexity of understanding the organisational implications of an effective OLC by demonstrating an indirect link through various other cultural norms, including innovation culture (when it comes to innovation performance) $[18,19]$ and digital culture (when it comes to sustainability performance) [20], to name a few. Indeed, such a challenge is compounded when introducing the notion of OA, particularly as it is characterised as a kind of organisational capability [21]. As will become evident throughout this work, shining a light on the link between organisational capabilities, learning culture, and organisational performance remains an open task and one which we endeavour to key into with the help of big data as a complementary phenomenon.

To help deal with these challenges, this paper adopts the notion of firm growth as a performance metric. This choice helps us avoid the pitfalls associated with the adoption of financial and non-financial metrics and also induces the notion of time, a contributing factor in the issues associated with differing financial performance implications [16]. In addition, this paper draws on dynamic capabilities theory, a widely used organisational theory reflecting the firm capabilities used in transformation [8], to help make sense of the complex nature of the relationships between knowledge-based and capability-based constructs [15]. More specifically, we adopt a hierarchical stance to dynamic capabilities, where lower-order (ordinary) capabilities help organisations perform day-to-day functions whilst higher-order (dynamic) capabilities help induce change in an organisations' resource base $[8,21]$. This hierarchy ultimately helps us to demonstrate how OA, as a higher-order dynamic capability, presents a valuable capability in achieving a sustained competitive advantage [22].

In adopting this perspective, we also recognise that dynamic capabilities are insufficient on their own; that is, to understand how they impact firm performance, the influence of lower-order capabilities should also be considered as a "dynamic bundle" [23,24].

To this end, we introduce big data capabilities (BDC), or digital technologies to manage large volumes of data [25], as a lower-order capability that helps shed some more light on the ambiguous relationship among OLC, OA, and organisational performance. Recent studies have demonstrated the link between digital technologies and dynamic capabilities needed for agility [2], perhaps more so in the context of agility in particular [3,26]. However, these studies do not consider distinguishing how the specific technologies might have varying impacts. Such an omission puts a damper on the understanding of how organisations can generate technology-related strategies with the aim of building agility [26]. In this paper, we delve into big data technologies, though as described next, making sense of their use in practice, particularly in grasping their place in an organisation's resource pool, leaves much to be desired.

The results appear to be mixed when it comes to contemporary work that investigates the interaction of big data capabilities and dynamic capabilities. For instance, some authors specifically refer to BDC as a dynamic capability in and of itself, having a significant influence on how organisations maintain the capability to adapt to changing circumstances [27]. Others suggest that BDC is a function of better management practices $[28,29]$, while others view $B D C$ as a lower-order capability $[30,31]$. Again, relying on dynamic capabilities theory, the expectation is that BDC can behave in an additive (complementary) fashion. BDC enables the transformation of organisational culture into actionable capabilities for ongoing 
organisational renewal, thus also acting as a conduit that can link the knowledge-based construct of OLC to higher-order dynamic capabilities.

Based on this, our contribution to the theory is twofold. First, we shed some more light on the nature of the interaction effects between OLC, OA, and firm-level performance by introducing the notion of "growth", which induces a time-based perspective. Secondly, we key into discussing the complex and ambiguous nature of interactions between knowledgebased and capability-based phenomena with a firm-level performance by introducing a dynamic bundle consisting of OLC, OA, and BDC. Thus, our intention is to contribute toward a more nuanced understanding of the relationship between knowledge-based and capability-based phenomena and ultimately provide some insights for the practical adoption of big data technologies to put OA and OLC to work in organisations.

In order to achieve this, the paper is structured as follows. Section 2 focuses on the extant literature and develops hypotheses to link the organisational learning culture and growth performance through OA's mediating impact. Section 3 describes the data and the research method, whilst Section 4 presents the analysis results, followed by a discussion in Section 5. The paper ends with the contributions to the literature, a summary of the limitations, and some suggestions for future research.

\section{Literature Review and Hypotheses Development}

\subsection{Organisational Learning Culture}

Organisational culture refers to a pattern of shared assumptions, beliefs, and expectations that guide members' interpretations and actions [11,32]. It also plays an essential role in shaping the managerial stance and appropriate organisational responses [33]. Thus, scholars have been interested in measuring culture's impact on company performance. However, different organisational values generate disparate behaviours with varying organisational outcomes $[11,30]$.

This study focuses on one type of culture, namely OLC, for two reasons. First, we define agility as a dynamic capability where learning is central in identifying problematic routines and adapting to changing market conditions [8,21]. Leaders need to build a motivational environment where human capital selects, acquires, transforms, and utilises knowledge for innovative purposes [34]. Second, organisational knowledge is initiated in ideas formed in individuals' minds and developed through communities of interaction [35]. These interactions are highly influenced by embedded culture in an organisation that fosters creativity and flexibility among employees [36]. As Fishbein and Ajzen [37] discussed, beliefs serve as the informational base driving attitudes, intentions, and behaviours in consecutive order.

A company with a more robust learning culture is better positioned to perceive market changes and learn from experience [38]. When the OLC improves, it is observed that employees are motivated to acquire, distribute, integrate, create, and transfer information and knowledge [39]. Having an OLC also positively influences organisational innovation, success, and sustainability [12]. Thus, it seems there are many reasons for managers to build a learning culture in their organisations.

Organisations that encourage a positive learning culture are more likely to promote knowledge sharing and improve productive job performance [39]. In addition, when shared norms and cultures are strongly enforced among members, it helps to encourage greater strategic alignment and goal attainment and generate innovations and agility [40] Thus, the OLC could connect training and learning to share, acquire, and exchange ideas internally and externally, eventually leading to enhanced innovative, operational, and financial performance [12,41,42]. Thus, as shown in Figure 1, this study hypothesises the following:

Hypothesis 1 (H1). The higher the OLC at a company, the greater its growth is. 


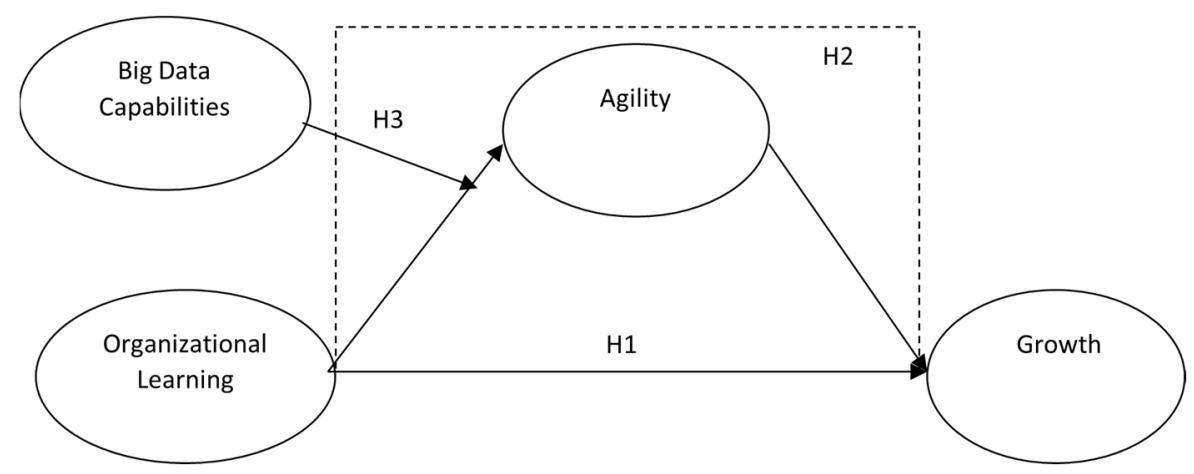

Figure 1. Research model. Note: The mediating hypothesis (H2) is shown with a dotted line.

\subsection{The Mediating Effect of Organisational Agility}

Adaptability is an organisation's readiness or mode, the top management's strategic inclination, or the propensity to initiate or conduct agility-related activities [43]. To some degree, it is a reactive aspect in its emphasising adjustment. However, organisations need to build capabilities, forming the basis for organisational agility [8]. This is because it should not be fair to expect a behaviour without a capacity for that behaviour [29,37].

Organisational agility is the firm's capability to sense the changes of the environment and respond to them to achieve sustainable competitive advantages that will help them survive in highly dynamic environments [5]. As discussed in the introduction, OA fits the definition of dynamic capabilities, being one of a firm's abilities to build, integrate, and reconfigure internal and external competencies in rapidly changing environments [8].

Creating new knowledge, skills, and processes to survive and become adaptable could be achieved through numerous activities such as risk-taking and experimentation $[8,43]$. Leaders could create a learning culture where individuals can feel free to improvise, experiment, and learn by trial and error [10]. Then, the learning culture results in a mental orientation and attitude that triggers an action or behaviour, such as adopting and using cloud technologies [44,45].

Sambamurthy et al. [6] stated that OA comprises three dimensions: (1) customer agility, (2) partnering agility, and (3) operational agility. Customer agility (CA) refers to integrating customers in the exploration and exploitation of innovation opportunities, hence helping to leverage the voice of customers to gain market intelligence. Partnering agility (PA) can tap into different stakeholders' assets, knowledge, and competencies, such as suppliers and distributors, to explore and exploit innovation opportunities. In this way, partnering agility helps to learn from business partners to enhance its response to the market. Operational agility (OpA) comprises an ability to accomplish speed, accuracy, and cost economy to exploit innovation opportunities. In other words, operational agility allows rapid process redesigns to exploit dynamic marketplace conditions.

Overall, OA's dimensions indicate how learning is key in agility. The adaptive process relies on a transformation from new knowledge, information, innovation, and learning. The top leader initiates this transformation, since ideas have to be advanced into the operational system through an "adaptive space" [2]. An OLC triggers this adaptive space or environment, since the development of an OLC can positively impact employee motivation to transfer learning and develop a positive adaptive attitude to change. Considering that actions will occur if a capability exists in an organisation, it is natural to expect that the accumulation of adaptability capacity eventually produces agility at the organisational level. Once companies have better agility, they can improve their productivity, adapt to threats, and introduce engagement and innovations that result in higher firm performance. In particular, the relationship between $\mathrm{OA}$ and growth has been the focus of researchers for years $[7,45]$. Hence, this study postulates the following:

Hypothesis 2 (H2). As an adaptability-prone capability in a company, organisational agility mediates the relation between OLC and growth performance. 


\subsection{Big Data Capabilities: Moderator of the Relationship between OLC and OA}

The information systems literature offers several studies indicating how information technology (IT) capabilities leverage IT systems to become agile [45]. In the same vein, digital technology capabilities could increase the exploitation of digital technologies for the benefit of organisational flexibility $[26,46]$. Digital technologies encompass a wide range of advances, some with highly limited applications such as 3D printing and others with a wide range of applications across industries such as big data. A wide range of affordances arises from digital technologies with numerous opportunities for companies [47,48]. Exploiting technologies entails improving and strengthening $\mathrm{OA}$ to sense the value of opportunities and facilitate their implementation within companies. Recent studies explored how individual digital technologies, such as big data, affect firms' agility and performance $[49,50]$. Following the empirical works $[6,45]$ that have shown the positive impact of IT competencies on shaping organisational agility and resulting in high firm performance, this study treats big data competencies as a moderating factor in the relationship between the OLC and OA.

Big data refers to vast volumes of data. It could be treated as a general-purpose technology which can change all aspects of production, consumption, and services by varying degrees of innovation [25]. Thus, company-level competencies (or capabilities) in understanding and using big data technologies could bring company growth by introducing new products, process innovations, cost reductions, and other innovations [51]. Recent research $[27,28]$ treats BDC as a dynamic capability affecting how organisations maintain the capability to adapt to changing circumstances. Mikalef et al. [31] argue that BDC, a lower-order capability, constitutes the routines or better management practices. Thus, BDC can behave in an additive fashion and transform an organisational culture into actionable capabilities for ongoing organisational renewal [30]. Hence, we purport that BDC could link the knowledge-based construct of an OLC to higher-order dynamic capabilities. Consequently, the study hypothesises the following:

Hypothesis 3 (H3). BDC positively moderates the impact of the OLC on OA.

\section{Research Design}

The following figure visualises the research study design (See Figure 2). Steps 1, 2, and 3 in the research method diagram have been mentioned in the previous parts, while steps 4 and 5 will be described in more detail in the following sections.

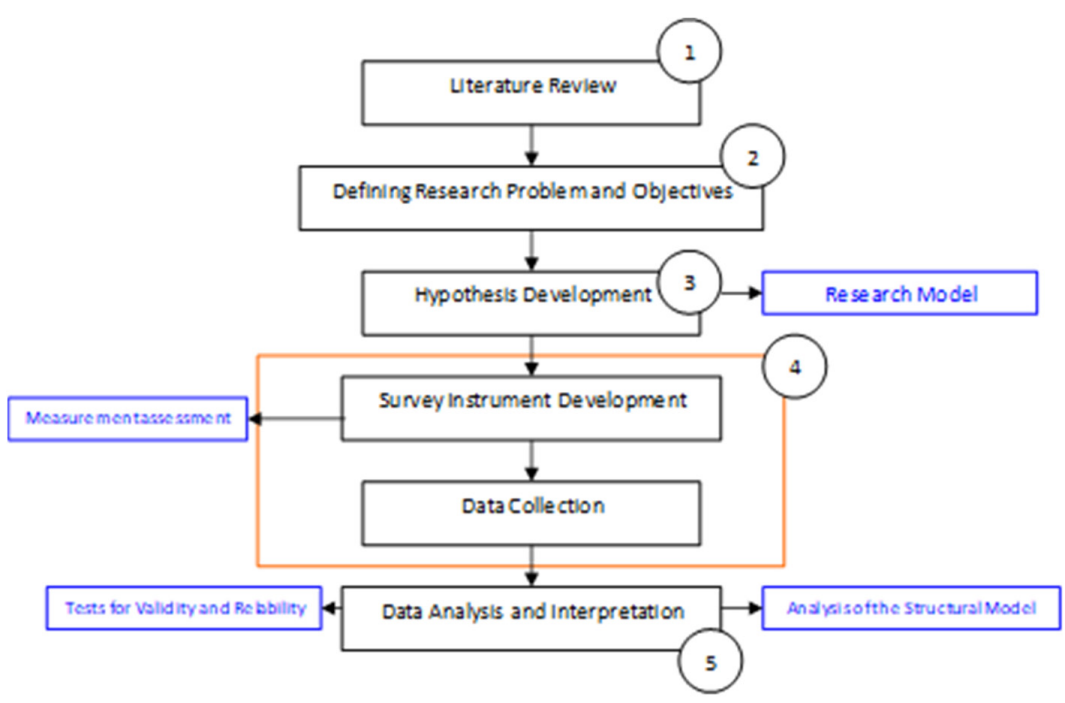

Figure 2. Research method diagram. 


\subsection{Measures}

Multi-item scales for OLC and OA were adopted from prior studies to measure the constructs and test the hypotheses mentioned above. Growth and big data competency were measured by asking the respondents directly, as shown in Appendix A. Each construct was measured using a 6-point Likert scale ranging from "strongly disagree" (1) to "strongly agree" (5).

In this paper, the OLC is an independent construct. A scale consisting of 6 items was adapted from the Dimensions of the Learning Organisation Questionnaire (DLOQ) [52]. One sample item is "In my organisation, people help each other learn."

To measure the companies' OA, an OA scale (6-point Likert scale) consisting of 3 dimensions-OpA, CA, and PA, each having 2 items-was adapted from Felipe et al. [5] and Sambamurthy et al. [6]. Some examples of the performance scale items are as follows: "Often rethinks their business model and creates their digital attack businesses" (OpA); "Thinks end-to-end about where digital efforts can produce a step-change in value for customers" (CA); and "Has an open structure for collaboration, and different organisations and processes for radical and incremental projects" (PA).

To measure the BDC, we asked the respondents to evaluate their companies' level in understanding big data analytics strategically and operationally on a 6-point Likert scale, ranging from "strongly disagree" (1) to "strongly agree" (5). Finally, for measuring organisational growth, we asked the respondents to rate the revenue growth performance of their businesses over the last 3 years, on a 5 -point Likert-type scale, including " $0 \%$ or less" (1), "1-5\%" (2), "6-10\%" (3), "11-20\%" (4), and "over 20\% (5)". Hence, this study utilised perceived growth (PG) as its performance measure.

Although not the focus of our study, turnover value was included as a control variable, as it may potentially mitigate any spurious interpretations of the findings. The respondents chose 1 of the 5 turnover values their company achieved in 2016: "less than AUD 10 million", “AUD 10.1-100 million", “AUD 101-250 million", “AUD 251-500 million", and "over AUD 500 million", where m refers to million. Then, their answers were coded as a 5-point Likert scale ranging from "less than AUD 10 million" (1) to "over AUD 500 million" (5).

Even though the extant literature suggests that the firm size or other characteristics can be involved as control variables for firm-level analyses, international business and marketing studies are prone to endogeneity issues [53]. Specifically, many researchers emphasise the routine consideration of endogeneity in international studies [54,55]. Moreover, some researchers even argue that PLS-SEM does not allow endogeneity to be addressed [56,57]. According to Hult et al. [54], between 2008 and 2017, none of the 43 reviewed PLS-SEM articles published in the Journal of International Marketing, International Marketing Review, and the Journal of International Business Studies - the three highest-ranked international marketing journals - tested for endogeneity. Since our study was conducted on a national sample (i.e., Australian companies), and we used the PLS- SEM technique, endogeneity was not an issue for our research.

\subsection{Sampling}

The research design included a sample of Australia's leading 247 companies whose leaders belonged to a professional organisation called the "CEO Circle." This group organises confidential networking for individuals working in CEO and C-level roles [58]. Since our study focused on leadership perspectives regarding culture, agility, and growth of firms, the "CEO Circle" provided access to individuals in CEO, C-level, and managing director roles across a diverse cross-section of organisations within Australia.

First, the CEO Circle member managers were contacted by telephone, and the aim of our study was explained to them. Of the 247 firm managers contacted, 223 agreed to work with this study, and eventually, 185 completed the questionnaire. The original data collection took place in 2016, and it included extra subsections covering strategy-focused questions. The initial data analysis was published as an executive report in 2017 [58]. This 
study derived from the survey by dropping the disruptive technology strategy section and focusing on questions related to organisational learning culture, agility, growth, and big data capabilities (see the survey questions in Appendix A).

After removing the surveys that had no growth data, the study ended with usable data from 138 companies. The respondents were 77 CEOs (56\%), 21 C-Level executive directors $(15 \%)$, and 40 other non-executive and business unit heads. In terms of turnover, $31 \%$ (43) of the firms had an annual turnover of over AUD 500 million, while $24 \%$ (34) had between AUD 10.1 and 100 million, 19\% (26) had between AUD 101 and 250 million, 14\% (19) had between AUD 251 and 500 million, and 11\% (16) had less than AUD 10 million. Our study represents a wide range of small, medium, and large companies. Moreover, 18 of the participant firms (13\%) were operating in the manufacturing industry, while $18(13 \%)$ were in finance and insurance, $14(10 \%)$ were in retail, $12(9 \%)$ in were ICT and technology, 12 $(9 \%)$ were in accounting services, $11(8 \%)$ were in health, and the rest (53 companies) were in other sectors.

\subsection{Assessment of Common Method Variance}

In order to test for common method variance (CMV), we used Harman's single factor [59] by exploratory factor analysis (EFA) with all variables loaded onto a single factor without a rotation. The new common latent factor explained only $21.73 \%$ of the variance, significantly less than the cut-off value of $50 \%$.

Kock [60] suggested that a model with greater than 3.3 variance inflation factors (VIFs) signals a CMV issue. The results of our VIF analysis (as seen in Table A1 in Appendix B) show that the VIF values ranged between 1.054 and 1.712 (i.e., the values were lower than the proposed threshold of 3.3). Accordingly, our model did not seem to be affected by common method bias.

\section{Analysis and Results}

The partial least squares structural equation model (PLS-SEM) technique was used to estimate the measurements and structural parameters [61]. We used the PLS-SEM technique to test our model based on several considerations. First, the PLS method can operate under a limited number of more discrete or continuous variables. Based on the fact that our sample was composed of 138 companies, PLS required the estimates to be more closely tied to the data than covariance structure analysis [62]. Finally, the innate ability to model second-order and other variables [63] was another reason for using this technique.

PLS is a structural equation modeling instrument that estimates the loadings and weights between items and constructs and produces standardised regression coefficients (i.e., b-coefficients) for the paths amongst the constructs. The analysis of a PLS model is composed of two phases:

(1) The analysis of the validity and reliability of the measurement model;

(2) The structural model tests.

This order certifies that the construct measures are valid and reliable before concluding the relationships among those constructs [61].

\subsection{Measurement Validation}

We estimated a null model with no structural relationships to assess the psychometric properties of the measurement instruments. Following Kleijnen et al. [64], this study used reflective indicators for all our constructs and estimated a null model with no structural relationships. We evaluated the reliability using composite scale reliability (CR), Cronbach's alpha, and the average variance extracted (AVE). Even though some scholars do not consider Cronbach's alpha necessary for Confirmative Factor Analysis (CFA), Cronbach's alpha reveals if the items of each factor are coherent within the factor or the latent variable. Thus, CFA is more related to validity, whereas Cronbach's alpha is more related to reliability. Hence, the author of [52] strongly recommended reporting Cronbach's alpha values for SEM analysis. For all measures, the PLS-based CR was well above the threshold value of 
0.70, Cronbach's alpha went beyond the threshold value of 0.60, and the AVE exceeded the 0.50 threshold value (see Table 1). In addition, we evaluated the convergent validity by inspecting the standardised loadings of the measures on their respective constructs and found that all measures exhibited standardised loadings that exceeded 0.60 .

Table 1. Measurement model (reflective factors).

\begin{tabular}{|c|c|c|c|c|c|}
\hline Constructs & Items & Loadings & AVE & CR & $\alpha$ \\
\hline \multirow{6}{*}{ OLC } & OLC_1 & 0.741 & 0.542 & 0.876 & 0.85 \\
\hline & OLC_2 & 0.727 & & & \\
\hline & OLC_3 & 0.672 & & & \\
\hline & $\mathrm{OLC}_{4} 4$ & 0.776 & & & \\
\hline & OLC_5 & 0.748 & & & \\
\hline & OLC_6 & 0.748 & & & \\
\hline \multirow{2}{*}{ OpA } & OpA_1 & 0.884 & 0.779 & 0.876 & 0.716 \\
\hline & OpA_2 & 0.881 & & & \\
\hline \multirow{2}{*}{ CA } & CA_1 & 0.842 & 0.741 & 0.851 & 0.659 \\
\hline & CA_2 & 0.879 & & & \\
\hline \multirow{2}{*}{ PA } & PA_1 & 0.842 & 0.717 & 0.835 & 0.606 \\
\hline & PA_2 & 0.852 & & & \\
\hline
\end{tabular}

Moreover, as a second-order variable, OA was estimated through a secondary factor analysis yielding three latent constructs: OpA, CA, and PA. Each of the three constructs had two indicators. Figure 3 shows the standardised regression loadings of those three given constructs, exceeding a standardised loading of over 0.60 . This result suggests that $\mathrm{OA}$, as a three-construct second-level variable, was significantly predicted by the OpA, CA, and PA.

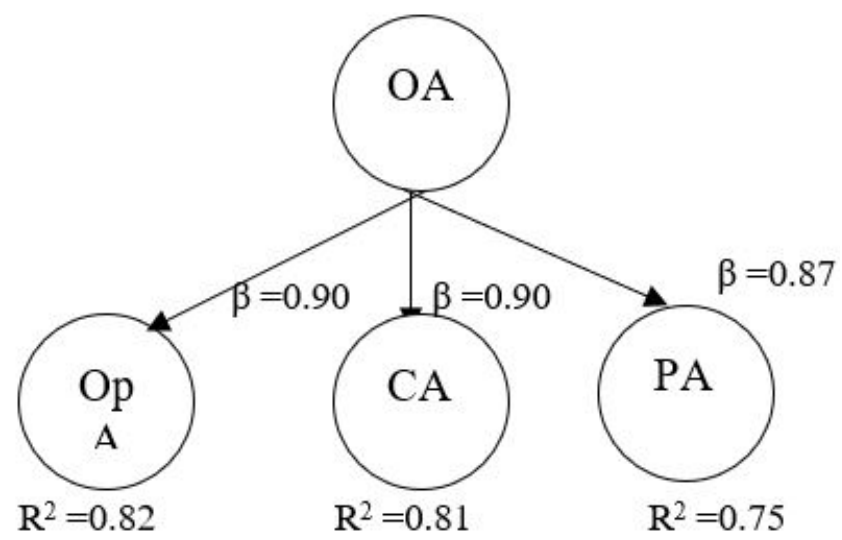

Figure 3. Second-order factor analysis of organisational agility.

We next assessed the discriminant validity of the measures. Table 2 shows the correlation among all variables, excluding the secondary data on firm performance, that provided further discriminant validity evidence. To fully satisfy the requirements for discriminant validity, the AVE for each multi-item construct should be expected to be greater than the squared correlation between constructs [62]. Such results suggest that the items shared more common variance with their respective constructs than those shared with other constructs. In the model, none of the inter-correlations of the constructs exceeded the square root of the AVE of the constructs. Moreover, as mentioned before, a VIF analysis (see Table A1 in Appendix B) showed that our VIF values ranged between 1.054 and 1.712. This result also provides empirical support regarding discriminant validity, implying no multi-collinearity. 
Table 2. Discriminant validity.

\begin{tabular}{lcccccccc}
\hline & & $\mathbf{1}$ & $\mathbf{2}$ & $\mathbf{3}$ & $\mathbf{4}$ & $\mathbf{5}$ & $\mathbf{6}$ & $\mathbf{7}$ \\
\hline 1 & BDC & - & & & & & & \\
2 & CA & 0.554 & $\mathbf{0 . 8 6 1}$ & & & & & \\
3 & OpA & 0.647 & 0.743 & $\mathbf{0 . 8 8 3}$ & & & & \\
4 & OLC & 0.448 & 0.555 & 0.485 & $\mathbf{0 . 7 3 6}$ & & & \\
5 & PA & 0.554 & 0.682 & 0.669 & 0.618 & $\mathbf{0 . 8 4 7}$ & & - \\
6 & PG & 0.253 & 0.366 & 0.262 & 0.283 & 0.297 & - & \\
7 & T & 0.123 & -0.003 & 0.032 & -0.244 & -0.137 & -0.188 & \\
& & & & & & & & \\
& CR & & 0.851 & 0.876 & 0.876 & 0.835 & & \\
& $\alpha$ & & 0.649 & 0.745 & 0.839 & 0.604 & & \\
& AVE & & 0.741 & 0.779 & 0.542 & 0.717 & &
\end{tabular}

Note: Values on the diagonal denote the square root of the AVE (in bold); BDC = big data capabilities, $\mathrm{PG}=$ perceived growth, $\mathrm{T}=$ turnover, $\mathrm{CR}=$ composite reliability, $\alpha=$ Cronbach's alpha.

\subsection{Hypothesis Testing}

The PLS approach [65] and the bootstrapping resampling method were employed using SmartPLS 3.0 software to estimate the main interaction and indirect effects and test the proposed model's hypotheses and predictive power. To determine the statistically significant links, the $t$-statistics were calculated for all coefficients, based on their stability across the sub-samples. The path coefficients and their associated $t$-values demonstrated the direction and impact of each hypothesised relationship. Following the suggestion of Chin et al. [66], a hierarchical approach for testing the hypotheses was employed. A model with indirect (mediation) effects in addition to the main effects (and covariates) was assessed, after which the interaction effects were added.

Table 3 shows the hypotheses, including the paths, betas, significance levels, and results. The findings provided no empirical evidence supporting a direct relationship between the OLC and PG, thus rejecting H1. The results also show that the OLC was positively and significantly related with $\mathrm{OA}(\beta=0.425 p<0.01)$, and OA was positively and significantly associated with PG $(\beta=0.304 p<0.01)$. Hence, the question arises about the indirect effect of the OLC on PG through OA (see H2), which will be examined in the mediation test.

Table 3. Path results.

\begin{tabular}{|c|c|c|c|c|c|}
\hline \multicolumn{3}{|c|}{ Relationships } & \multirow{2}{*}{$\begin{array}{c}\text { Path Coefficient }(\beta) \\
0.056\end{array}$} & \multirow{2}{*}{$\begin{array}{c}\text { Hypotheses } \\
\text { H1 }\end{array}$} & \multirow{2}{*}{$\begin{array}{c}\text { Results } \\
\text { Not } \\
\text { Supported }\end{array}$} \\
\hline OLC & $\rightarrow$ & PG & & & \\
\hline OLC & $\rightarrow$ & $\mathrm{OA}$ & $0.425^{* *}$ & & \\
\hline $\mathrm{OA}$ & $\rightarrow$ & PG & $0.304^{* *}$ & & \\
\hline $\mathrm{T}$ & $\rightarrow$ & PG & $0.163^{* *}$ & & \\
\hline $\mathrm{OLC} * \mathrm{BDC}$ & $\rightarrow$ & $\mathrm{OA}$ & $0.123^{* *}$ & H3 & Supported \\
\hline
\end{tabular}

A two-step construction procedure was employed to address the hypotheses concerning BDC's moderating effects (i.e., H3) [66]. The PLS approach allows for explicit estimation of the standardised latent variable scores after saving the obtained results [67]. Here, each item of the OLC and BDC was standardised. Following this procedure, the standardised question items were multiplied. As shown in Table 3, the results demonstrated a positive interaction effect between the OLC $(\beta=0.13, p<0.01)$ and OA, supporting H3.

In order to see how the relationship between the OLC and PG differed due to the BDC, we also conducted a simple slope analysis (see Figure 4). The graphic shows how the relationship between OA and OLC differed due to the BDC level. The association between the OLC and OA became stronger when the BDC was higher. Accordingly, we provided further empirical evidence in support of the moderator role of BDC. 


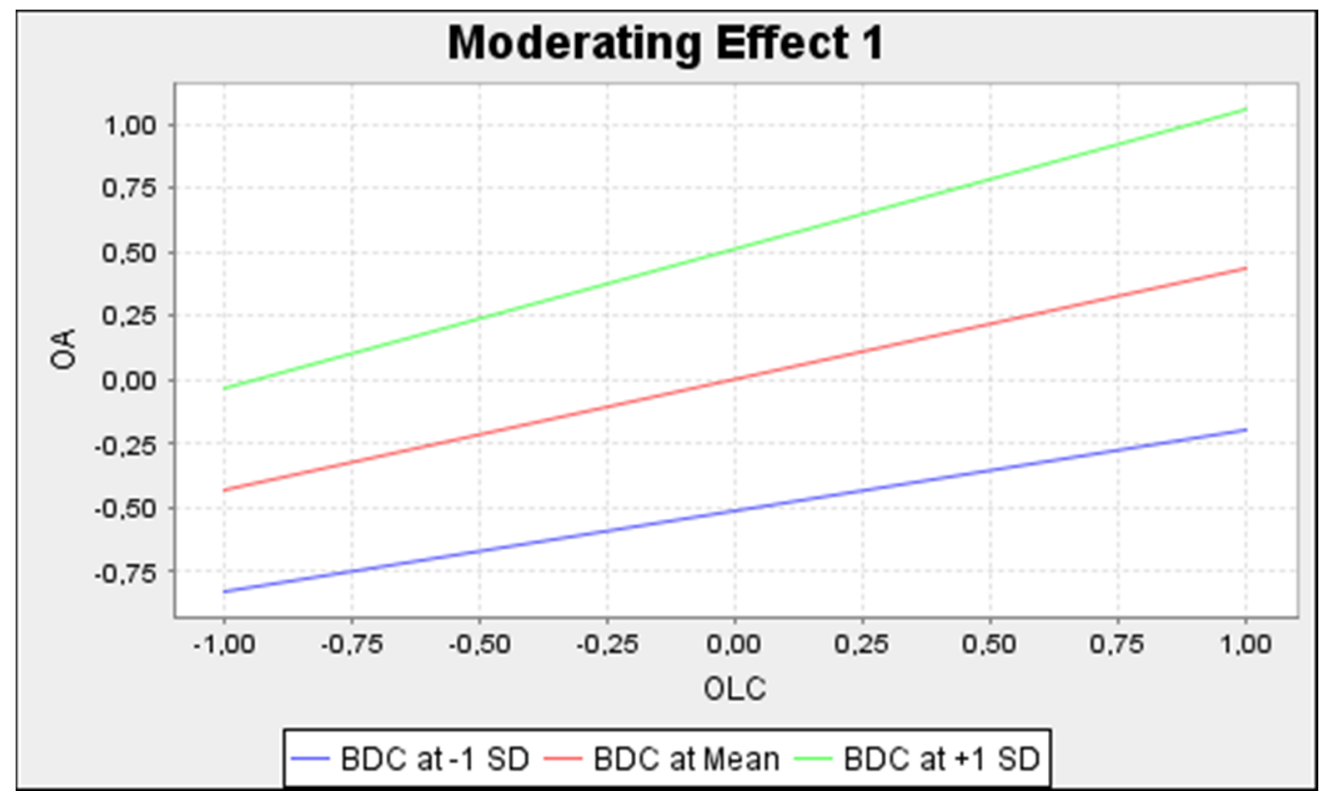

Figure 4. Simple slope analysis.

\subsection{Structural Model}

In order to validate the PLS-SEM approach, various quality scores, such as the coefficient of determination $\left(\mathrm{R}^{2}\right)$ [66] and standardised root mean square residual (SRMR) [67], were considered. The $\mathrm{R}^{2}$ values of the endogenous constructs were used to evaluate the model fit and indicate how well the data points fit a line or curve. As suggested by Chin [66], the categorisation of $R^{2}$ values was small $\left(0.02 \leq R^{2}<0.13\right)$, medium $\left(0.13 \leq R^{2}<0.26\right)$, or large $\left(0.26 \leq R^{2}\right)$. The endogenous constructs' $R^{2}$ statistic values were used to assess the model fit [67]. Table 4 shows the $\mathrm{R}^{2}$ values as the fit measures of the structural model. According to the main effect model outcomes, OA performance $\left(R^{2}=0.393\right)$ had a large effect, while PG $\left(\mathrm{R}^{2}=0.151\right)$ had a medium effect. Caused by BDC's interaction effect, the $\mathrm{R}^{2}$ for PG's value in the final model was 0.151 , again reflecting a medium effect size. The $\mathrm{R}^{2}$ for OA's value was 0.582 , again reflecting a large (but this time higher) effect size (see Table 4).

Table 4. Structural model.

\begin{tabular}{|c|c|c|c|}
\hline Fit Measures & Endogenous Constructs & Main Effect Model & Final Model \\
\hline \multirow{2}{*}{$\mathrm{R}^{2}$} & OA & 0.393 & 0.582 \\
\hline & PG & 0.151 & 0.151 \\
\hline \multicolumn{2}{|c|}{ SRMR } & 0.076 & 0.072 \\
\hline
\end{tabular}

Note: PG = perceived growth.

Though the model fit criteria (SRMR, NFI, d_ULS, d_G, and Chi_square) for PLS-SEM are early and often not useful for PLS-SEM, we also reported these key criteria in this study. This shows that the SRMR was 0.076 in the main effect model, while it was lower in the final model (SRMR: 0.072). Although the Normed Fit Index (NFI) is commonly used to evaluate the model fit for SmartPLS, it is not available for second-order PLS models. Hence, we did not involve that index value. As a result, the developed model seemed to have an overall model fit based on these criteria, even though those explications were difficult to comprehend for the applied subject. Therefore, we can conclude that the developed structural model had good predictive power and was satisfactory, as shown in Figure 5. 


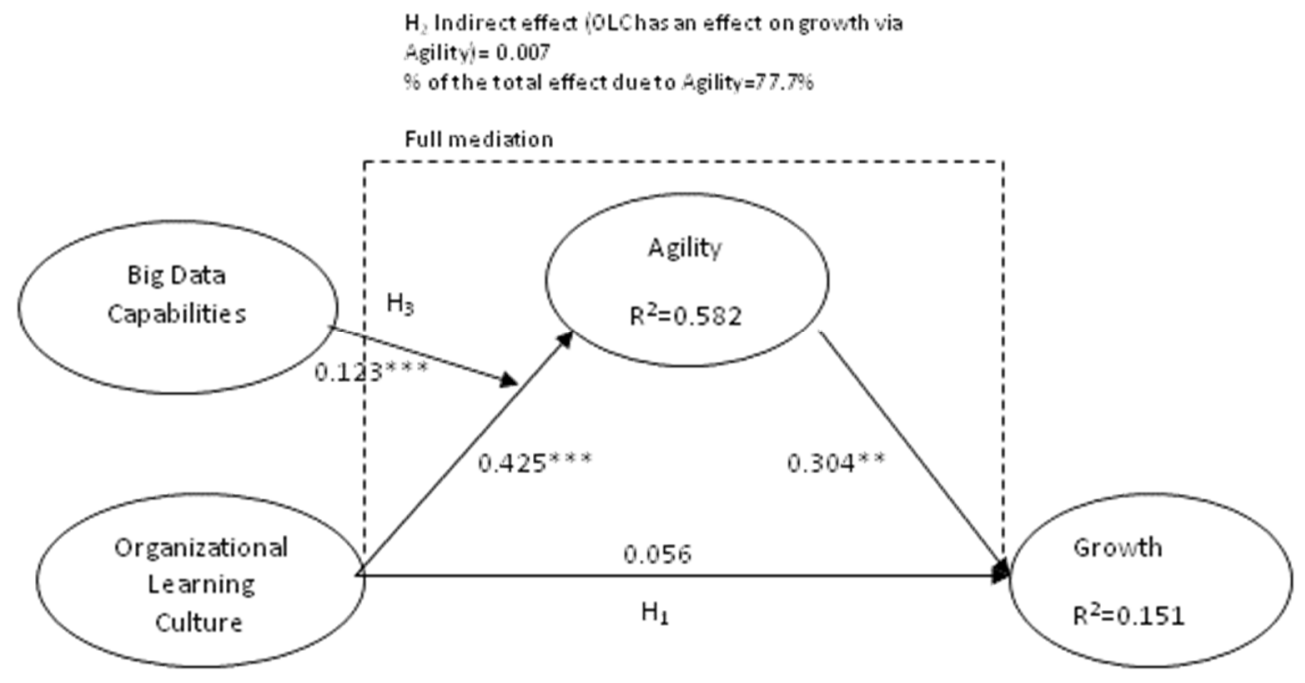

Figure 5. Structural model results. Note: ${ }^{* *} p<0.001 ;{ }^{* *} p<0.01$.

\subsection{Mediation Test}

Tests of mediation were conducted by investigating the significance of the indirect paths that arose from the independent to the dependent variables, using the bootstrapping procedures associated with SmartPLS. While examining the mediating effects, past studies have underlined the bootstrapping approach as being superior to the alternative methods of testing indirect effects, such as the Sobel test, regarding power and type I and II error rates [68]. The significance of the indirect effects was analysed both in the absence of the intervening variable(s) (total effects and denoted $C$ paths) and with their existence (direct effects and denoted C' paths). Baron and Kenny's [69] procedure for testing mediation was followed. Moreover, the effect ratios were calculated to demonstrate the total effect explained by the indirect effects via the mediator(s). This ratio seemed to be a preferable (quantitative) way to describe the mediated effects, overwhelming the full or partial mediation dichotomous distinction, provided that no suppression effects were present in the model [70]. The analyses were potentially facilitated by maximizing the effect sizes between the intervention and controls.

Table 5 shows the mediation analyses' results for exploring OA's role as the mediator between the OLC and PG. The results show that OA fully mediated the effect of the OLC on PG, with $78 \%$ of the total effect (effect ratio of 0.78 ) being explained by OA. Accordingly, $\mathrm{H} 2$ was supported.

Table 5. Tests of mediation in the structural model.

\begin{tabular}{ccccc}
\hline \multicolumn{2}{c}{ Relationships } & Total Effect C Path & Total Effect C'Path & \multirow{2}{*}{ Effect Ratio } \\
\cline { 1 - 4 } From & To & Estimate & Estimate & \\
\hline OLC & PG & $0.252^{*}$ & 0.056 & 0.777 \\
\hline Note: PG $=$ perceived growth. ${ }^{*} p<0.05$. & &
\end{tabular}

\section{Discussion}

Knowledge is arguably one of the most important resources organisations have under their control, not the least when adapting to (or inducing) changes in the marketplace [71]. Thus, effectively creating and disseminating this knowledge throughout an organisation is a core capability for sustained competitive advantage [72]. However, this is not straightforward, as such a capability often needs to be built, nurtured, and ultimately embedded into the way an organisation conducts its business [8] (i.e., organisations should hold a learning culture if they are to survive in the long term).

Our results support the premise that an OLC is a key yet insufficient ingredient in an organisation's pursuit of continuous growth. Like others (e.g., [73]), we found that 
the value of holding an OLC only came into play through the development of dynamic capabilities. Then, the OLC ultimately led to organisational performance, thus providing further evidence to support the viewpoint of learning mechanisms, such as the OLC, giving rise to higher-order dynamic capabilities [40]. However, when it comes to an understanding of the foundations (such as BDC) that support this process of capability building, our results pose some interesting conclusions.

In our case, BDC presented themselves as enablers for successfully transforming an effective learning culture into actionable capabilities for inducing and adapting to change. The results suggest that, aside from being an important precursor for dynamic capabilities, BDC hold additive (complementary) qualities by bolstering the knowledge creation and dissemination activities stemming from an OLC, which are then used to help with strategic choices in maintaining evolutionary fitness. This resembles a so-called "dynamic bundle" [23] that helps to further explicate the still ambiguous role (and interdependencies) of lower-order capabilities (BDC) and higher-order dynamic capabilities (OA), though it also includes a knowledge-based element of the OLC, thus further demonstrating a successful integration of disparate views on organisations [73].

Such a bundle of capabilities, culture, and learning mechanisms also helps demonstrate how capabilities can be embedded and modified through an organisational culture, something that remains difficult to grasp [74]. As is still the case, (learning) culture seems to be one of the most challenging themes for agile organisations [75], particularly when shifting from an exploitative mode of operation to one that is more exploratory [38]. Often, this shift would involve introducing conflicting goals, values, and practices that would have to coexist depending on the strategy being adopted. Our study, like most, reinforced the power of an effective learning culture in leveraging change. However, we also demonstrated how BDC can potentially resolve (or leverage) such an organisational paradox. Indeed, how BDC should be adopted in times of learning or organisational change to cope with these conflicting themes is still a key question involving a wide range of contingencies, including, for instance, environmental dynamism and technological change [76,77]. Though our data could not directly substantiate this impact, we provided preliminary insight into this as a platform for future studies.

\section{Conclusions}

This paper observes the relationships among the OLC, OA, BDC, and growth performance. The search for how agility delivers better firm performance has recently been a popular topic [26]. However, agility does not occur in a vacuum; rather, it is a product of the company culture. Thus, our study offers a model to explain how the OLC triggers a chain effect through its influence on OA, resulting in company growth (behaviour) performance. Consistent with the hypotheses developed in the model, we showed the positive relationship between the OLC and growth performance only through full mediation. Hence, we could confidently highlight that the OLC did not generate growth, strengthening the argument that managers should generate a learning culture to embed attitudes for behavioural change.

This paper considered OA as a desired dynamic capability for companies striving for survival in turbulent environments based on dynamic capabilities theory. Another interesting finding indicated the key role of BDC in amplifying the impact of the OLC on $\mathrm{OA}$. These findings pointed out that firm leadership should facilitate an effective learning environment and build big data competencies through the efficient use of technologies to survive the stringent competition and perform well. Thus, this paper highlighted that building capabilities in organisations, including OA and BDC, could enrich each other and build a solid base to deliver successful organisational growth.

\subsection{Implications for Theory}

Our study contributes to dynamic capabilities theory in two main ways. First, considering that dynamic capabilities theory is instrumental in understanding organisational 
performance $[8,29,71]$, our data explains how $\mathrm{OA}$ as a dynamic capability affects organisational performance by transferring the OLC into growth (i.e., a construct we adopted to help counter the ambiguous outcomes from financial and non-financial performance metrics). Second, taking on the complex and ambiguous role of BDC in fostering a more responsive and flexible organisation, we demonstrated how BDC can act as part of a complementary "dynamic bundle" $[23,24]$, shedding light on the interaction effects between knowledge-based phenomenon (OLC), lower-order capabilities (BDC), dynamic capabilities (OA), and firm-level performance. Indeed, the influence of learning in the dynamic capabilities schema is not so straightforward and leaves much room for refinement [78]. In line with others [73], we observed that the OLC acted as a precursor for and facilitator of organisational renewal, going back to the fundamental notion of building dynamic capabilities through learning [40]. What is interesting here is the fact that BDC (characterised as a lower-order capability) appeared to bolster the efficacy of a learning culture in enabling ongoing organisational renewal, leading to firm-level growth. Thus, BDC did not appear to be a substitute for the OLC and did not disrupt the efforts of a learning culture in building dynamic capabilities. Generally, learning from big data poses significant challenges for organisations, not the least being when it comes to making sense of the learning this technology can bring [76]. Mastering this capability requires a conscious effort for learning in new and flexible ways [76]. Thus, perhaps "learning to unlearn" [79] becomes a characteristic of such a capability. This finding brings it further to the notion of second-order capabilities [79], the likes of which do not necessarily work to keep the organisation running efficiently (like lower-order capabilities would typically be regarded as performing) but rather help the organisation build first-order dynamic capabilities themselves. Because this runs somewhat counter to the idea of BDC as dynamic capabilities [27], it would be interesting to observe the interaction effects of BDC on the relationship between dynamic capabilities and firm-level performance outcomes to help provide some more insight into this phenomenon, perhaps proving a fruitful notion for further research.

\subsection{Implications for Practice}

Concerning practical implications, this study proposes two contributions. First, managers should empower their employees by $\mathrm{OA}$ and $\mathrm{BDC}$, with the knowledge that their most important tool to fight dynamic market pressures is, to a large extent, linked to their ability to make effective use of big data. Managing data will improve leadership by bringing workforces on board and equipping them with the necessary capability sets $[36,80]$. This study clearly shows how big data competencies helped to utilise the OLC to become effective in OA.

A second practical implication involves the importance of culture for leadership. Leaders should consider understanding, building, and sustaining a learning culture as part of their leadership roles. They should be better trained in building healthy cultures and aligning culture and strategy [81]. An abundance of research in leadership and organisational culture $[36,50,74]$ clarifies that building strong cultures can play a significant role in the innovativeness of organisations. Therefore, overlooking organisational cultures can cost organisations and their employees, customers, and stakeholders.

A final remark to managers and leaders within companies is that OA is built over a strong learning culture, so they should consider how to flourish this dynamic capability within their company environments. They might try different structures and human resource practices to build a strong learning culture [81]. They should also find ways of improving their agility by emphasising the performance of different agility dimensions such as customer, operational, and partnering agility. Understanding nuanced information in each agility dimension could help efficient technology management to create their competitive advantage. 


\subsection{Limitations and Suggestions for Future Research}

A few limitations should be noted, along with questions for future research. First, since using cross-sectional data is one of the significant limitations of this research, questions are raised about the causal direction and purpose of the relationship among the constructs. Even though surveying is considered a standard method for research in the business environment, the method used (only questionnaire) may not provide objective measures and results about the flow of knowledge. For example, it is unclear how the agility within customer relationships, operations, and partnership relationships is a dynamic phenomenon in the management context. Due to cross-sectional data and restricted time issues, scholars should collect longitudinal data.

Second, and probably foremost, the data are self-reported. Even though organisational researchers are not fond of using self-reports, they cannot do without them, as the practical usefulness of those measures makes them virtually essential in many research contexts [82]. Indeed, self-reports are not as limiting as once commonly asserted [83]. The extant literature provides evidence regarding the more precise estimates of self-reports than the behavioural measures [84]. For instance, using self-reported and perceptual indicators versus objective ones is a rising issue in performance measurement.

Many studies have provided empirical evidence supporting a strong correlation between objective and self-reported performance measures [85]. The present results provide evidence of relationships among the variables. Moreover, to go beyond the hesitations regarding self-reported measures for perceived growth, we also attempted to gather objective measures for growth. However, only 44 of 138 companies publicly shared actual growth data. Hence, we decided to check our results by conducting the same tests on the sample of 44 firms. The results obtained from this smaller sample were very similar to the previous ones, except for the moderating effect of BDC (See Table A2 in Appendix B).

Third, this study considered turnover a control variable, while many other factors such as firm size or human resource practices [14] might play a role in growth. Future studies could enrich the investigation to determine the significant factors that might increase our understanding of the interplay among the OLC, OA, and growth.

Moreover, the sample size was also limited $(n=138)$. However, since our initial sample comprised 247 companies whose top managers were members of the CEO Circle in Australia, we gathered data from $57 \%$ of our initial sample, proving a good ratio. Moreover, we chose the CEO Circle to reach out to senior executives who could direct us in the right direction for the macro-level leadership topics under investigation in this research.

Fourth, our study was conducted in Australia, and it was hard to generalise. Future studies could conduct comparative studies and gather large datasets to allow comparisons and the deriving of theoretical and practical lessons regarding the relationship between the OLC, OA, BDC, and growth.

Finally, this study explored OA's mediating role as a three-dimensional composite construct, composed of operational agility, customer agility, and partnering agility, on the relationship between the OLC and growth. There is still a lack of consensus regarding the content of OA in the management literature. Different dimensions could be related to $\mathrm{OA}$ as a multifaceted concept, thus proving to be an interesting future research topic. Indeed, two findings of this study point out promising future study avenues. First, our finding that the OLC did not directly affect growth is a research question that could prove intriguing for researchers. More studies should conduct empirical studies to cross-examine the explanatory power of OA as a dynamic capability in strengthening the benefits of digital technologies such as big data. Second, this study demonstrates that BDC influences the impact of the OLC on OA as a complementary bundle consisting of lower-order capabilities, higher-order (dynamic) capabilities, and the knowledge-based construct of the OLC. Further research is encouraged to examine the contingencies surrounding their relationships to draw a more fine-grained picture of how individuals use big data to translate organisational culture to a dynamic capability for ongoing organisational change based on innovations. 
Author Contributions: Data curation, S.B. and M.K.; Formal analysis, M.K. and A.G.; Investigation, D.C., M.K., S.B. and A.G.; Methodology, A.G. and M.K.; Project administration, S.B.; Writing-original draft, D.C. and M.K.; Writing-review \& editing, D.C., M.K. All authors have read and agreed to the published version of the manuscript.

Funding: This research had no external funding.

Institutional Review Board Statement: This research received ethical approval by UTS (HREC2015000488).

Informed Consent Statement: Informed consent was obtained from all subjects involved in the study.

Data Availability Statement: Except survey, all data is publically available as given in the references.

Conflicts of Interest: The authors declare no conflict of interest.

\section{Appendix A. Questionnaire}

1. What is your current position in your company or your last executive position?

CEO

Other C-Level Executive

Business Unit Head

Non-Executive Director

Senior Executive

2. Organisational name of your company:

3. Industry category (select one)

1. Agricultural, Forestry, and Fishing

10. Finance and Insurance

2. Mining and Metals

3. Manufacturing

4. Utilities

11. Property

5. Construction

6. Retail

7. Hospitality

8. Transport

9. ICT and Technology

12. Government

13. Education

14. Health

15. NGO

16. Other (please specify)

17. Consulting Services

18. Industrial Services

4. What is your organisational size by annual turnover?

Less than AUD 10 million

AUD 10.1-100 million

AUD 101-250 million

AUD 251-500 million

Over AUD 500 million

5. During the last 3 years, how much, on average, has your organisation's business grown annually in Australia?

$0 \%$ or less

$1-5 \%$

$6-10 \%$

$11-20 \%$

Over $20 \%$ 
6. Organisational learning culture.

\begin{tabular}{|c|c|c|c|c|c|c|}
\hline My Organisation & $\begin{array}{l}\text { Strongly } \\
\text { Disagree }\end{array}$ & Disagree & $\begin{array}{l}\text { Slightly } \\
\text { Disagree }\end{array}$ & $\begin{array}{l}\text { Slightly } \\
\text { Agree }\end{array}$ & Agree & $\begin{array}{c}\text { Strongly } \\
\text { Agree }\end{array}$ \\
\hline $\begin{array}{l}\text { Has the necessary } \\
\text { network of leaders to } \\
\text { build a learning culture }\end{array}$ & & & & & & \\
\hline $\begin{array}{l}\text { Views all staff as } \\
\text { entrepreneurs }\end{array}$ & & & & & & \\
\hline $\begin{array}{l}\text { Encourages open and } \\
\text { honest communication }\end{array}$ & & & & & & \\
\hline $\begin{array}{l}\text { Has built a network of } \\
\text { innovation resources } \\
\text { internally and externally }\end{array}$ & & & & & & \\
\hline $\begin{array}{l}\text { Actively encourages and } \\
\text { rewards people who } \\
\text { generate or drive } \\
\text { new ideas }\end{array}$ & & & & & & \\
\hline $\begin{array}{l}\text { Encourages learning and } \\
\text { self-improvement in its } \\
\text { people and allows } \\
\text { sufficient freedom for this }\end{array}$ & & & & & & \\
\hline
\end{tabular}

7. Organisational agility.

\begin{tabular}{|c|c|c|c|c|c|c|}
\hline My Organisation & $\begin{array}{l}\text { Strongly } \\
\text { Disagree }\end{array}$ & Disagree & $\begin{array}{l}\text { Slightly } \\
\text { Disagree }\end{array}$ & $\begin{array}{l}\text { Slightly } \\
\text { Agree }\end{array}$ & Agree & $\begin{array}{c}\text { Strongly } \\
\text { Agree }\end{array}$ \\
\hline \multicolumn{7}{|l|}{ Operational agility } \\
\hline \multicolumn{7}{|l|}{$\begin{array}{l}\text { Often rethinks their } \\
\text { business model and } \\
\text { create their digital } \\
\text { attack businesses }\end{array}$} \\
\hline \multicolumn{7}{|l|}{$\begin{array}{l}\text { Targets information } \\
\text { technology internally and } \\
\text { externally to mine for a } \\
\text { new project, ideas, design, } \\
\text { and delivery platforms }\end{array}$} \\
\hline \multicolumn{7}{|l|}{ Collaborative agility } \\
\hline \multicolumn{7}{|l|}{$\begin{array}{l}\text { Frequently tests and } \\
\text { refines or prototypes } \\
\text { products and strategies in } \\
\text { close cooperation } \\
\text { with customers }\end{array}$} \\
\hline \multicolumn{7}{|l|}{$\begin{array}{l}\text { Thinks end-to-end about } \\
\text { where digital efforts can } \\
\text { produce a step change in } \\
\text { value for customers }\end{array}$} \\
\hline \multicolumn{7}{|l|}{ Partnering agility } \\
\hline \multicolumn{7}{|l|}{$\begin{array}{l}\text { Has an open structure for } \\
\text { collaboration and } \\
\text { different organisations } \\
\text { and processes for radical } \\
\text { and incremental projects }\end{array}$} \\
\hline $\begin{array}{l}\text { Secures their place in a } \\
\text { network of companies, } \\
\text { institutions, and } \\
\text { customers to interact and } \\
\text { create mutual value }\end{array}$ & & & & & & \\
\hline
\end{tabular}


8. Expected share of an organisation's overall growth that will result from digital efforts in the next 3 years.

\begin{tabular}{|c|c|c|c|c|c|}
\hline & $\leq 4 \%$ & $5-9 \%$ & $10-14 \%$ & $\geq 15 \%$ & $\begin{array}{l}\text { Do Not } \\
\text { Know }\end{array}$ \\
\hline \multicolumn{6}{|c|}{ Expected share of overall growth from digital programmes } \\
\hline \multicolumn{6}{|l|}{$\begin{array}{l}\text { Creating a new business or exploring new } \\
\text { profit pools }\end{array}$} \\
\hline \multicolumn{6}{|l|}{$\begin{array}{l}\text { Building competitive advantage in an existing } \\
\text { business }\end{array}$} \\
\hline \multicolumn{6}{|l|}{$\begin{array}{l}\text { Improving existing business and keeping pace } \\
\text { with competitors }\end{array}$} \\
\hline \multicolumn{6}{|l|}{ Cutting costs to improve operating margins } \\
\hline Overall expected growth & & & & & \\
\hline
\end{tabular}

9. Big data capabilities.

\begin{tabular}{|c|c|c|c|c|c|c|}
\hline My Organisation & $\begin{array}{l}\text { Strongly } \\
\text { Disagree }\end{array}$ & Disagree & $\begin{array}{l}\text { Slightly } \\
\text { Disagree }\end{array}$ & $\begin{array}{c}\text { Slightly } \\
\text { Agree }\end{array}$ & Agree & $\begin{array}{c}\text { Strongly } \\
\text { Agree }\end{array}$ \\
\hline $\begin{array}{l}\text { Has a good } \\
\text { understanding of big } \\
\text { fata's impact, both } \\
\text { strategically and } \\
\text { operationally }\end{array}$ & & & & & & \\
\hline
\end{tabular}

\section{Appendix B. Supporting Statistical Analyses}

Table A1. VIF values.

\begin{tabular}{ccc}
\hline & OA & PG \\
\hline BDC & 1299 & \\
OLC ${ }^{*}$ BDC & 1054 & 1712 \\
OLC & 1306 & 1712 \\
OA & & \\
PG & & \\
\hline
\end{tabular}

Note: OLC $=$ organisational learning culture; OA = organisational agility; BDC: big data capabilities PG: perceived growth.

Table A2. Path result for the smaller sample.

\begin{tabular}{cccc}
\hline & Relationships & & Path Coefficient ( $\beta)$ \\
\hline OLC & $\rightarrow$ & PG & 0.056 \\
OLC & $\rightarrow$ & OA & $0.246^{*}$ \\
OA & $\rightarrow$ & G & $0.275^{*}$ \\
T & $\rightarrow$ & G & 0.087 \\
OLC ${ }^{*}$ BDC & $\rightarrow$ & OA & 0.092 \\
\hline
\end{tabular}

Note: $\mathrm{OLC}=$ organisational learning culture; OA = organisational agility; OpA = operational agility; $\mathrm{CA}=$ customer agility; PA = partnering agility; BDC: big data capabilities; G: perceived growth; T: turnover. ${ }^{*} p<0.05$.

\section{References}

1. Birkinshaw, J.; Zimmermann, A.; Raisch, S. How do firms adapt to discontinuous change? Calif. Manag. Rev. 2016, 58, 36-58. [CrossRef]

2. Uhl-Bien, M.; Arena, M. Leadership for organisational adaptability. Leadersh. Q. 2018, 29, 89-104. [CrossRef]

3. Troise, C.; Corvello, V.; Ghobadian, A.; O'Regan, N. How can SMEs successfully navigate VUCA environment: The role of agility in the digital transformation era. Tech. Forecast. Soc. Chang. 2022, 174, 121227. [CrossRef]

4. Baur, J.E.; Parker, E.B.; Buckley, M.R.; Ferris, G.R.; Allison, T.H.; McKenny, A.F.; Short, J.C. More than oneway to articulate a vision. Leadersh. Q. 2016, 27, 156-171. [CrossRef] 
5. Felipe, C.M.; José, L.; Roldán, J.L.; Leal-Rodríguez, A.L. An explanatory and predictive model for organisational agility. J. Bus. Res. 2016, 69, 4624-4631. [CrossRef]

6. Sambamurthy, V.; Bharadwaj, A.; Grover, V. Shaping agility through digital options. MIS Q. 2003, 27, 237-263. [CrossRef]

7. Amazon. Organisational agility's role in the growth of Amazon. Strateg. Dir. 2019, 35, 27-29. [CrossRef]

8. Teece, D.; Peteraf, M.; Leih, S. Dynamic capabilities and organisational agility. Calif. Manag. Rev. 2016, 58, 13-35. [CrossRef]

9. Andriopoulos, C.; Lewis, M.W. Managing innovation paradoxes. Long Range Plan. 2010, 43, 104-122. [CrossRef]

10. Cepeda, G.; Vera, D. Dynamic capabilities and operational capabilities. J. Bus. Res. 2007, 60, 426-437. [CrossRef]

11. Cameron, K.S.; Quinn, R.E. Diagnosing and Changing Organisational Culture: Based on the Competing Values Framework, 3rd ed.; Jossey-Bass: San Fransisco, CA, USA, 2011.

12. Lin, C.Y.; Huang, C.K.; Zhang, H. Enhancing employee job satisfaction via e-learning. Int. J. Hum. Comput. Interact. 2019, 35, 584-595. [CrossRef]

13. Chatman, J.A.; Caldwell, D.F.; O'reilly, C.A.; Doerr, B. Parsing organisational culture. J. Organ. Behav. 2014, 35, 785-808. [CrossRef]

14. Egan, T.M.; Yang, B.; Bartlett, K.R. The effects of organisational learning culture and job satisfaction on motivation to transfer learning and turnover intention. Hum. Resour. Dev. Q. 2004, 15, 279-301. [CrossRef]

15. Hung, R.Y.Y.; Yang, B.; Lien, B.Y.-H.; McLean, G.N.; Kuo, Y.-M. Dynamic capability: Impact of process alignment and organizational learning culture on performance. J. World Bus. 2010, 45, 285-294. [CrossRef]

16. Škerlavaj, M.; Dimovski, V.; Černe, M.; Kekenovski, L.; Tevdovski, D.; Trpkova, M. The organisational learning culture and organisational performance in Macedonian companies. Eur. J. Int. Manag. 2011, 5, 574-607. [CrossRef]

17. Choi, I. Moving beyond mandates: Organizational learning culture, empowerment, and performance. Int. J. Public Admin. 2020, 43, 724-735. [CrossRef]

18. Černe, M.; Jaklič, M.; Škerlavaj, M.; Aydinlik, A.Ü.; Polat, D.D. Organizational learning culture and innovativeness in Turkish firms. J. Manag. Organ. 2012, 18, 193-219. [CrossRef]

19. Hoonsopon, D.; Puriwat, W. Organizational agility: Key to the success of new product development. IEEE Trans. Eng. Manag. 2021, 68, 1722-1733. [CrossRef]

20. Hadi, S.; Baskaran, S. Examining sustainable business performance determinants in Malaysia upstream petroleum industry. J. Clean. Prod. 2021, 294, 126231. [CrossRef]

21. Winter, S.G. Understanding dynamic capabilities. Strateg. Manag. J. 2003, 24, 991-995. [CrossRef]

22. Dixon, S.; Meyer, K.; Day, M. Building dynamic capabilities of adaptation and innovation. Long Range Plan. 2014, 47, 186-205. [CrossRef]

23. Peteraf, M.; Di Stefano, G.; Verona, G. The elephant in the room of dynamic capabilities: Bringing two diverging conversations together. Strateg. Manag. J. 2013, 34, 1389-1410. [CrossRef]

24. Waleczek, P.; von den Driesch, T.; Flatten, T.C.; Brettel, M. On the dynamic bundles behind operations management and research and development. Eur. Manag. J. 2019, 37, 175-187. [CrossRef]

25. Davenport, T. Big Data at Work; Harvard Business Review Press: Boston, MA, USA, 2014.

26. Mrugalska, B.; Ahmed, J. Organizational agility in industry 4.0: A systematic literature review. Sustainability 2021, $13,8272$. [CrossRef]

27. Rialti, R.; Marzi, G.; Caputo, A.; Mayah, K.A. Achieving strategic flexibility in the era of big data. Manag. Decis. 2020, 58, 1585-1600. [CrossRef]

28. Henao-García, E.; Arias-Pérez, J.; Lozada, N. Fostering big data analytics capability through process innovation: Is management innovation the missing link? Bus. Inf. Rev. 2021, 38, 28-39. [CrossRef]

29. Katic, M.; Cetindamar, D.; Agarwal, R. Deploying ambidexterity through better management practices: The case of High-Variety, Low-Volume Manufacturing. J. Manuf. Technol. Manag. 2021, 32. [CrossRef]

30. Ciampi, F.; Demi, S.; Magrini, A.; Marzi, G.; Papa, A. Exploring the impact of big data analytics capabilities on business model innovation: The mediating role of entrepreneurial orientation. J. Bus. Res. 2021, 123, 1-13. [CrossRef]

31. Mikalef, P.; Boura, M.; Lekakos, G.; Krogstie, J. Big data analytics capabilities and innovation: The mediating role of dynamic capabilities and moderating effect of the environment. Br. J. Manag. 2019, 30, 272-298. [CrossRef]

32. Fiol, C. Managing culture as a competitive resource. J. Manag. 1991, 17, 191-211.

33. Schein, E.H. Organisational Culture and Leadership; Jossey-Bass: San Francisco, CA, USA, 1985.

34. Naqshbandi, M.M.; Tabche, I. The interplay of leadership, absorptive capacity, and organisational learning culture in open innovation. Technol. Forecast. Soc. Chang. 2018, 133, 156-167. [CrossRef]

35. Lubatkin, M.H.; Simsek, Z.; Ling, Y.; Veiga, J.F. Ambidexterity and performance in small- to medium-sized firms. J. Manag. 2006, 32, 646-672.

36. Sims, H.P.; Faraj, S.; Yun, S. When should a leader be directive or empowering? Bus. Horiz. 2009, 52, 149-158. [CrossRef]

37. Fishbein, M.; Ajzen, I. Belief, Attitude, Intention, and Behavior: An Introduction to Theory and Research; Addison-Wesley: Reading, MA, USA, 1975.

38. March, J.G. Exploration and exploitation in organizational learning. Organ. Sci. 1991, 2, 71-87. [CrossRef]

39. Swift, P.E.; Hwang, A. The impact of affective and cognitive trust on knowledge sharing and organizational learning. Learn. Organ. 2013, 20, 20-37. [CrossRef]

40. Zollo, M.; Winter, S.G. Deliberate learning and the evolution of dynamic capabilities. Organ. Sci. 2002, 13, 339-351. [CrossRef] 
41. Jamali, D.; Sidani, Y.; Zouein, C. The learning organisation. Learn. Organ. 2009, 16, 103-121. [CrossRef]

42. Mazur, J.; Zaborek, P. Organisational culture and open innovation performance in Small and Medium-sized Enterprises in Poland. Int. J. Manag. Econ. 2016, 51, 104-138. [CrossRef]

43. Gioia, D.A.; Patvardhan, S.D.; Hamilton, A.L.; Corley, K.G. Organisational identity formation and change. Acad. Manag. Ann. 2013, 7, 123-193. [CrossRef]

44. Fis, M.A.; Cetindamar, D. Unlocking the relationship between corporate entrepreneurship and firm performance. Entrep. Res. J. 2021, 11, 1-47. [CrossRef]

45. Cetindamar, D.; Abedin, B.; Shirahada, K. The role of employees in digital transformation: Application of the Theory of Planned Behavior on Australian employees' cloud technology usage. IEEE Trans. Eng. Manag. 2021. [CrossRef]

46. Ferreira, J.J.M.; Fernandes, C.I.; Ferreira, F.A.F. To be or not to be digital that is the question. J. Bus. Res. 2019, 101, 583-590. [CrossRef]

47. Autio, E.; Nambisan, S.; Thomas, L.D.; Wright, M. Digital affordances, spatial affordances, and the genesis of entrepreneurial ecosystems. Strat. Entrep. J. 2018, 12, 72-95. [CrossRef]

48. Subramaniam, M.; Iyer, B.; Venkatraman, V. Competing in digital ecosystems. Bus. Horiz. 2019, 62, 83-94. [CrossRef]

49. Barlette, Y.; Baillette, P. Big data analytics in turbulent contexts: Towards organizational change for enhanced agility. Prod. Plan. Control 2020. [CrossRef]

50. Ashrafi, A.; Ravasan, A.Z.; Trkman, P.; Afshari, S. The role of business analytics capabilities in bolstering firms' agility and performance. Int. J. Inf. Manag. 2019, 47, 1-15. [CrossRef]

51. Gunasekaran, A.; Papadopoulos, T.; Dubey, R.; Wamba, S.F.; Childe, S.J.; Hazen, B.; Akter, S. Big data and predictive analytics for supply chain and organisational performance. J. Bus. Res. 2017, 70, 308-317. [CrossRef]

52. Marsick, V.J.; Watkins, K.E. Demonstrating the value of an organisation's learning culture. Adv. Dev. Hum. Resour. 2003, 5, 132-151. [CrossRef]

53. Sinkovics, R.R.; Deng, Z.; Kim, D.; Yuan, X. Assessing endogeneity issues in international marketing research. Int. Mark. Rev. 2016, 33, 483-512.

54. Hult, G.T.M.; Hair, J.F., Jr.; Proksch, D.; Sarstedt, M.; Pinkwart, A.; Ringle, C.M. Addressing endogeneity in international marketing applications of partial least squares structural equation modeling. J. Int. Market. 2018, 26, 1-21. [CrossRef]

55. Sande, J.B.; Ghosh, M. Endogeneity in survey research. Int. J. Res. Market. 2018, 35, 185-204. [CrossRef]

56. Antonakis, J.; Bendahan, S.; Jacquart, P.; Lalive, R. On making causal claims: A review and recommendations. Leadersh. Q. 2010, 21, 1086-1120. [CrossRef]

57. McIntosh, C.N.; Edwards, J.R.; Antonakis, J. Reflections on Partial Least Squares Path Modeling. Organ. Res. Methods 2014, 17, 210-251. [CrossRef]

58. Burdon, S.W. How to Harness Disruptive Technology and Foster an Innovation Culture; Criteria Publishing: Sydney, Australia, 2017.

59. Harman, H.H. Modern Factor Analysis; University of Chicago Press: Chicago, IL, USA, 1960.

60. Kock, N. Common method bias in PLS-SEM: A full collinearity assessment approach. Int. J. e-Collab. 2015, 11, 1-10. [CrossRef]

61. Hair, J.F.; Hult, G.T.M.; Ringle, C.; Sarstedt, M. A Primer on Partial Least Squares Structural Equation Modeling (PLS-SEM); SAGE Publications: Thousand Oaks, CA, USA, 2017.

62. Fornell, C.G.; Cha, J. Partial least squares. In Advanced Methods of Marketing Research; Bagozzi, R.P., Ed.; Blackwell: Oxford, UK, 1994; pp. 52-78.

63. Peng, D.X.; Lai, F. Using partial least squares in operations management research. J. Oper. Manag. 2012, 30, 467-480. [CrossRef]

64. Kleijnen, M.; De Ruyter, K.; Wetzels, M. An assessment of value creation in mobile service delivery and the moderating role of time consciousness. J. Retail. 2007, 83, 33-46. [CrossRef]

65. Ringle, C.M.; Wende, S.; Becker, J.-M. SmartPLS 3; SmartPLS: Bönningstedt, Germany, 2015.

66. Chin, W.W.; Marcolin, B.L.; Newsted, P.R. A partial least squares latent variable modeling approach for measuring interaction effects. Inf. Syst. Res. 2003, 14, 189-217. [CrossRef]

67. Tenenhaus, M.; Vinzi, V.E.; Chatelin, Y.M.; Lauro, C. PLS path modeling. Comput. Stat. Data Anal. 2005, 48, 159-205. [CrossRef]

68. MacKinnon, D.P.; Lockwood, C.M.; Williams, J. Confidence limits for the indirect effect. Multivar. Behav. Res. 2004, 39, 99-128. [CrossRef] [PubMed]

69. Baron, R.M.; Kenny, D.A. The moderator-mediator variable distinction in social psychological research. J. Personal. Soc. Psychol. Bull. 1986, 51, 1173-1182. [CrossRef]

70. Shrout, P.E.; Bolger, N. Mediation in experimental and nonexperimental studies: New procedures and recommendations. Psychol. Methods 2002, 7, 422-445. [CrossRef] [PubMed]

71. Helfat, C.E.; Raubitschek, R.S. Dynamic and integrative capabilities for profiting from innovation in digital platform-based ecosystems. Res. Policy 2018, 47, 1391-1399. [CrossRef]

72. Pereira, V.; Bamel, U. Extending the resource and knowledge based view: A critical analysis into its theoretical evolution and future research directions. J. Bus. Res. 2021, 132, 557-570. [CrossRef]

73. Cetindamar, D.; Phaal, R. Technology management in the age of digital technologies. IEEE Trans. Eng. Manag. 2021. [CrossRef]

74. Bertels, S.; Howard-Grenville, J.; Pek, S. Cultural molding, shielding, and shoring at Oilco: The role of culture in the integration of routines. Organ. Sci. 2016, 27, 573-593. [CrossRef] 
75. Ahlbäck, K.; Fahrbac, C.; Murarka, M.; Salo, O. How to Create an Agile Organization. 2017. Available online: https://www. mckinsey.com/business-functions/organization/our-insights/how-to-create-an-agile-organization (accessed on 3 May 2021).

76. Calvard, T.S. Big data, organizational learning, and sensemaking: Theorizing interpretive challenges under conditions of dynamic complexity. Manag. Learn. 2016, 47, 65-82. [CrossRef]

77. Hosoya, R.; Kamioka, T. Understanding How the Ad Hoc Use of Big Data Analytics Impacts Agility: A Sensemaking-Based Model. In Proceedings of the 2018 International Conference on Advances in Big Data, Computing and Data Communication Systems (icABCD), Durban, South Africa, 6-7 August 2018; pp. 1-8.

78. Schilke, O.; Hu, S.; Helfat, C.E. Quo vadis, dynamic capabilities? A content-analytic review of the current state of knowledge and recommendations for future research. Acad. Manag. Ann. 2018, 12, 390-439. [CrossRef]

79. Schilke, O. Second-order dynamic capabilities: How do they matter? Acad. Manag. Perspect. 2014, 28, 368-380. [CrossRef]

80. Jia, J.; Yan, J.; Jahanshahi, A.A.; Lin, W. What makes employees more proactive? Asia Pac. J. Hum. Resour. 2020, 58, 107-127. [CrossRef]

81. Carmeli, A.; Waldman, D.A. Leadership, behavioral context, and the performance of work groups in a knowledge-intensive setting. J. Technol. Trans. 2010, 35, 384-400. [CrossRef]

82. Podsakoff, P.M.; Organ, D.W. Self-reports in organizational research: Problems and prospects. J. Manag. 1986, 12, 531-544. [CrossRef]

83. Tjosvold, D.; Tang, M.M.L.; West, M. Reflexivity for team innovation in China. Group Organ. Manag. 2004, 29, 540-559. [CrossRef]

84. Howard, G.S. Why do people say nasty things about self-reports? J. Organ. Behav. 1994, 15, 399-404. [CrossRef]

85. Richard, P.J.; Devinney, T.M.; Yip, G.S.; Johnson, G. Measuring organizational performance. J. Manag. 2009, 35, 718-804. 